\title{
Photosynthetic performance and growth traits in Pennisetum centrasiaticum exposed to drought and rewatering under different soil nutrient regimes
}

\author{
Yayong Luo $\cdot$ Xueyong Zhao $\cdot$ Hao Qu \\ Xiaoan Zuo $\cdot$ Shaokun Wang $\cdot$ Wenda Huang $\cdot$ \\ Yongqing Luo $\cdot$ Min Chen
}

Received: 26 May 2013/Revised: 11 October 2013/Accepted: 14 October 2013/Published online: 9 November 2013

(C) The Author(s) 2013. This article is published with open access at Springerlink.com

\begin{abstract}
Responses of plants exposed to drought and rewatering have been well documented; however, little is known concerning strategies of psammophyte to drought and rewatering under different soil nutrient regimes. For this study, Pennisetum centrasiaticum under two soil nutrient regimes was subjected to progressive drought and subsequent rewatering. Soil water status, gas exchange characteristics, chlorophyll $a$ fluorescence characteristics as well as biomass traits were measured to investigate ecophysiological responses. Net photosynthesis rate $\left(P_{\mathrm{n}}\right)$, stomatal conductance $\left(g_{\mathrm{s}}\right)$, water use efficiency, maximum quantum efficiency of photosynthesis system II (PSII, $F_{\mathrm{V}} /$ $F_{\mathrm{M}}$ ), electron transport flux per cross section $\left(\mathrm{ET}_{0} / \mathrm{CS}_{0}\right)$, and performance index on cross section basis $\left(\mathrm{PI}_{\mathrm{CS}}\right)$ were suppressed during drought periods for both nutrient regimes. Meanwhile, leaf intercellular $\mathrm{CO}_{2}$ concentration $\left(C_{i}\right)$, minimal fluorescence intensity $\left(F_{0}\right)$, and dissipated energy flux per cross section $\left(\mathrm{DI}_{0} / \mathrm{CS}_{0}\right)$ increased. Reversible downregulation of PSII photochemistry and enhanced thermal dissipation of excess excitation energy $\left(\mathrm{DI}_{0} / \mathrm{CS}_{0}\right)$ contributed to enhanced photo-protection in drought-stressed plants. Thus, the results indicate that $P$. centrasiaticum is capable of withstanding and surviving extreme drought events, and the recovery pattern of stressed $P$. centrasiaticum under both nutrient regimes was similar. However, fertilization increased the biomass and
\end{abstract}

Communicated by L. A. Kleczkowski.

Y. Luo $(\bowtie) \cdot X$. Zhao $\cdot$ H. Qu $\cdot$ X. Zuo $\cdot$ S. Wang

W. Huang $\cdot$ Y. Luo $\cdot$ M. Chen

Department of Ecology and Agriculture, Cold and Arid Regions of Environmental and Engineering Research Institute, Chinese Academy of Sciences, No. 320 Donggang West Road, Lanzhou 730000, Gansu, China

e-mail: luoyy@1zb.ac.cn the variation in gas exchange and chlorophyll $a$ fluorescence characteristics during drought periods. Additionally, fertilization accelerated the process of drought and aggravated stress under extreme drought events. Thus, the fertilization strategy used in $P$. centrasiaticum restoration should be carefully selected-fertilization may not always be beneficial.

Keywords Pennisetum centrasiaticum · Drought and rewatering · Nutrient $\cdot$ Photosynthesis .

Chlorophyll $a$ fluorescence

\section{Introduction}

Water and nutrients are critical resources for plant life and associated physiological processes. The supply of water and nutrients in arid and semi-arid ecosystems usually is so low that plants repeatedly suffer from water and nutrient deficiency (Chen et al. 2005; Miyashita et al. 2005). Additionally, desertification processes usually result in significant decreases in soil nutrient levels (Zhou et al. 2008; Zhao et al. 2009).

Water is the crucial limiting factor for plant recruitment, photosynthesis, growth, and net ecosystem productivity in arid ecosystems. Hence, arid ecosystems rapidly respond to precipitation events (Xu et al. 2007). The responses of crops and trees to soil drought and rewatering are well documented (Ortuno et al. 2005; Galle et al. 2007; PerezPerez et al. 2007; Santesteban et al. 2009), but little is known about the specialized strategies of psammophytes dealing with drought and rewatering. It is known that vegetative growth of stressed plants can recover after rewatering (Galle et al. 2007; Luo et al. 2011), suggesting a reversibility of physiological changes generated by water 
deficiency. However, the mechanisms of recovery from drought have not been fully elucidated (Galle et al. 2007).

Physiological responses of plants to nutrient availability are well documented. For example, Chen et al. (2005) and Wu et al. (2008) reported a significant and positive correlation between photosynthetic capacity and leaf nutrient content. An increase of nutrient availability might improve photosynthetic capacity or stomatal control under waterand nutrient-deficit conditions. A report suggested that nitrogen-deficient plants accumulated more abscisic acid and were therefore predisposed to respond more rapidly to water stress (Radin and Ackerson 1981). Conversely, Lin et al. (2012) found that nitrogen-fertilized maize responded more rapidly to increasing water stress. In addition, Chen et al. (2005) mentioned that in two grasses, varying nitrogen addition did not alter the gas exchange characteristics under water stress. The inconsistent results might at least partly be induced by species characteristics, native environment, the overall level of nutrient availability, and water stress levels. This topic clearly needs further attention.

The Horqin Sandy Land is one of the most seriously desertification-threatened areas in China (Andrén et al. 1994). Vegetation in this area can survive long drought periods and recover at precipitation events, but there is only scattered information on the physiological mechanisms involved. Pennisetum centrasiaticum is the dominant perennial in these sandy lands. A study of its responses to drought and rewatering conditions will contribute to understanding the physiological characteristics of recovery from drought stress, as well as the main limiting processes under drought and nutrient stress. The response of $P$. centrasiaticum to soil drought and rewatering process under two different nutrient regimes was therefore examined. Gas exchange characteristics, chlorophyll $a$ fluorescence, total biomass, and its allocation between shoot and root were the main examined variables.

The main focus of this study thus is on processes involved in the photosynthetic adaptation to drought stress, and the recovery from drought after rewatering under different nutrient regimes. The following questions were addressed:

1. Can nutrient addition improve photosynthetic capacity of $P$. centrasiaticum under drought and rewatering conditions?

2. Which processes are involved in drought tolerance and recovery in $P$. centrasiaticum?

\section{Materials and methods}

\section{Experimental design}

This study was conducted at the south-western $\left(42^{\circ} 55^{\prime} \mathrm{N}\right.$, $120^{\circ} 44^{\prime} \mathrm{E}$; approximately $360 \mathrm{~m}$ ASL) Horqin Sandy Land.
This area has a temperate, semi-arid, and continental monsoon climate, receiving $360 \mathrm{~mm}$ annual mean rainfall, with $75 \%$ of it occurring between June and September. Annual mean latent evaporation is $1,935 \mathrm{~mm}$. A number of psammophytes dominate, including $P$. centrasiaticum, Aristida adscensionis, Salsola collina, Agriophyllum squarrosum, Cleistogenes squarrosa, Chloris virgata, Caragana microphylla, Lespedeza davurica, Artemisia halodendron, and Artemisia frigida.

Budding $P$. centrasiaticum root segments from the sand dune biotope were transplanted into $27.6-\mathrm{cm}$ diameter and $26.5-\mathrm{cm}$ deep plastic pots containing sandy soil on 22 April 2009. Water content at saturation and field capacity of the sandy soil was 20.15 and $12.41 \%$, respectively. Bulk density was $1,530 \mathrm{~g} \mathrm{~m}^{-3}$. Before transplanting, a fertilizer was applied when the root segments were transferred to pots: High nutrients, where $20 \mathrm{~g}$ of slow-release fertilizer 'Osmocote' NPK (14:14:14) was added per pot. This corresponds to soil nutrient levels in the properly restored sandy land (Huang et al. 2009). Half of the pots, Low nutrients, received no additional supplement (total $\mathrm{N}$ content of the original sandy soil was $49-53 \mathrm{mg} \mathrm{kg}^{-1}$ ). For each of the two nutrient levels, 30 pots with three $10-\mathrm{cm}$ root segments per pot were arranged in an equilateral triangle and kept in open-air environment with well irrigation until the onset of water treatments. Excess water was allowed to drain through holes at the bottom of the pots. Water treatments were started when leaves were completely developed and mature. For each nutrient treatment, 18 pots ( 9 pots per water treatment) with uniformly sized $P$. centrasiaticum were selected. All pots were placed under a mobile rain shelter, drawn over the pots at rainfall, and then removed after rain. To avoid edge effects, the position of each treatment was changed every week. The well-watered plants were then watered to field capacity every day during the experimental period. Stressed plants were kept without water until net photosynthesis approached zero and the soil volumetric water content approached $3 \%$ during the late morning. In total, water was withheld for 11 days (13 June to 24 June) and 17 days (13 June to 30 June), for high and low nutrients, respectively, then rewatered until net photosynthesis had recovered to that of the well watered for each nutrient regime, respectively. The nine pots per water treatment were divided into two groups: six pots were used for testing gas exchange, chlorophyll $a$ fluorescence, and sampling; the other three pots were used to measure the biomass traits at the end of the experiment. Through 24 days (13 June to 6 July), gas exchange and chlorophyll $a$ fluorescence were measured on naturally expanded leaves at five randomly selected plants from six pots per treatment every 2 days, except for measurements on 25 June, when drought-stressed plants with fertilization were revived on the next day of rewatering. 
The plants in the other three pots were harvested on 6 July when the experiment was complete, to measure biomass traits. (Note: initially, there was another water treatment with natural conditions. The drought process here was hampered by irregular rains, and some plants were partly dead in the late growing season, so the eco-physiological data from this treatment are not included here.)

Soil water status and climatic data

Soil volumetric water content at $0-$ to $20-\mathrm{cm}$ depth was measured from 8:00 to 8:30 using a TDR probe (TRIMEPICO TDR, Imko Company, Germany). Rainfall was measured with a ground-level tipping-bucket rain gauge. Photosynthetic active radiation (PAR), air temperature, and relative humidity were recorded with a portable photosynthesis system (LI-6400, LI-COR Inc., Lincoln, NE, USA).

Leaf gas exchange and chlorophyll $a$ fluorescence measurement

The net photosynthetic rate $\left(P_{\mathrm{n}}\right)$, transpiration rate $\left(T_{\mathrm{r}}\right)$, stomatal conductance $\left(g_{\mathrm{s}}\right)$, and intercellular $\mathrm{CO}_{2}$ concentration $\left(C_{i}\right)$ were measured from 9:00 to 11:00 using a portable photosynthesis system. The measurements were conducted on mature and expanded leaves of five different plants per treatment under uniform conditions (block temperature $30{ }^{\circ} \mathrm{C}, \quad 360-390 \mu \mathrm{mol} \quad\left(\mathrm{CO}_{2}\right) \mathrm{mol}^{-1}$, and $1,500 \mu \mathrm{mol} \mathrm{m} \mathrm{m}^{-2} \mathrm{~s}^{-1}$ of PAR (provided by a built-in red LED light source). The ratio of $P_{\mathrm{n}}$ to $T_{\mathrm{r}}$ was calculated to determine instantaneous water use efficiency (WUE).

Measurements of chlorophyll $a$ fluorescence and gas exchange were carried out on the same leaf. The maximum quantum efficiency of PSII, photosynthesis system II, $\left(F_{\mathrm{V}} /\right.$ $\left.F_{\mathrm{M}}\right)$, minimal fluorescence intensity $\left(F_{0}\right)$, electron transport flux per cross section $\left(\mathrm{ET}_{0} / \mathrm{CS}_{0}\right)$, dissipated energy flux per cross section $\left(\mathrm{DI}_{0} / \mathrm{CS}_{0}\right)$, and performance index on cross section basis $\left(\mathrm{PI}_{\mathrm{CS}}\right)$ were measured using a portable plant efficiency analyzer (Handy-PEA, Hansatech, King's Lynn, UK). After dark adaptation for $20 \mathrm{~min}$, the measurements were conducted with an excitation light of $3,000 \mu \mathrm{mol} \mathrm{m} \mathrm{m}^{-2} \mathrm{~s}^{-1}$ for $1 \mathrm{~s}$.

\section{Biomass traits}

Three pots from each treatment were selected for measurement of biomass traits. Each plant was separated into above- and belowground biomass. Roots were washed to remove soil and weighed after oven-drying to constant mass at $80{ }^{\circ} \mathrm{C}$ and the dry mass root:shoot ratio was calculated.
Statistic analysis

Student's $t$ test analyses on independent samples of leaf gas exchange and chlorophyll $a$ fluorescence parameters $(n=5)$ were performed, respectively, testing for significant differences $(P<0.05)$ between water-stressed and well-watered plants on each day measurements were taken (Galle et al. 2007). The GLM process was used to examine the effects of irrigation regimes, nutrient regimes, and their interactions on biomass and biomass allocation between shoot and root. The data were log-transformed before analysis if necessary and all statistical procedures were carried out using SPSS 19.0 software.

\section{Results}

Environmental conditions and water status

The climatic conditions during the experimental periods were typical of summer in Horqin Sandy Land. Photosynthetic active radiation (PAR), relative air humidity, and air temperature on the sampling days through experiment ranged between 1,085 and $1,689 \mu \mathrm{mol} \mathrm{m}{ }^{-2} \mathrm{~s}^{-1}, 24.4$ and $47.6 \%$, and 29.2 and $33.6{ }^{\circ} \mathrm{C}$, respectively (Fig. 1). Ambient $\mathrm{CO}_{2}$ concentration ranged between 360 and $390 \mu \mathrm{mol}\left(\mathrm{CO}_{2}\right)$ $\mathrm{mol}^{-1}$ throughout the whole experimental period.

Soil volumetric water content in drought-stressed plants dropped to $4.1 \%$ during 17 days and to $3.2 \%$ during 11 days for unfertilized and fertilized $P$. centrasiaticum, respectively (Fig. 2). Fertilization resulted in an accelerated loss of water. After rewatering, soil water status was restored immediately to the well-watered level, which remained stable until the end of rewatering periods. The well-watered plant treatment

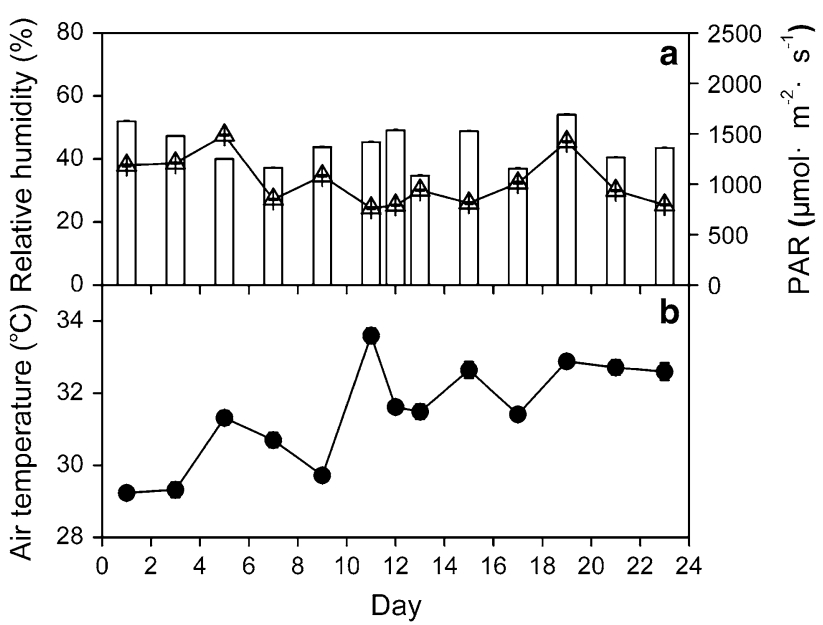

Fig. 1 Changes in photosynthetic active radiation (PAR) (columns), relative humidity of air (filled triangle line), (a) and air temperature (b) for each sampling day through experiment. Values are mean $\pm \mathrm{SE}$ $(n=5)$ 

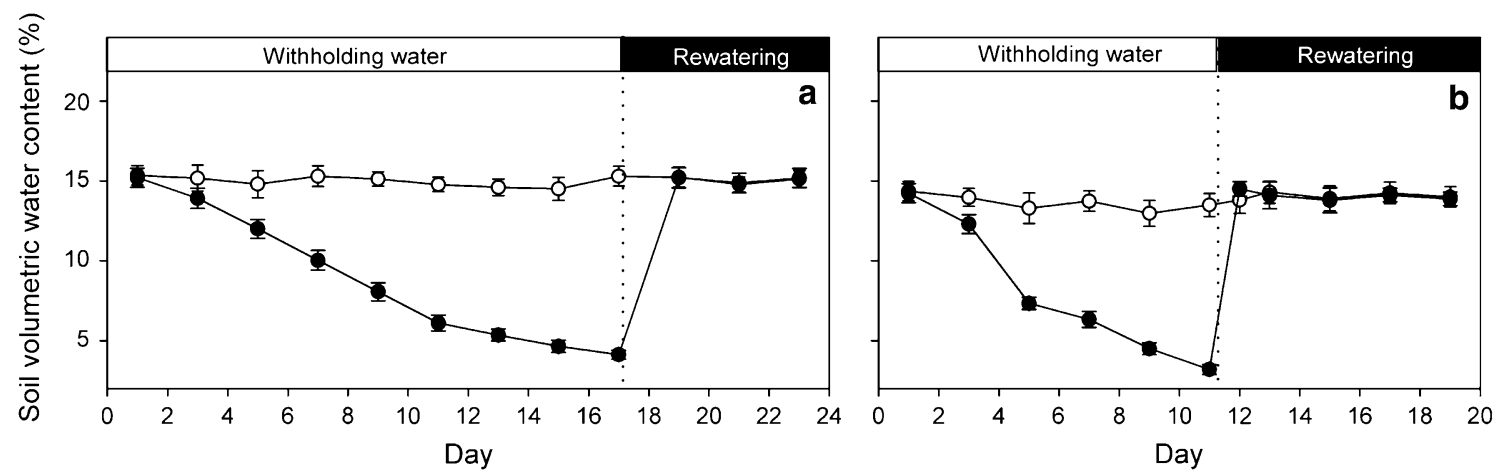

Fig. 2 Changes in soil volumetric water content during soil drought and rewatering for unfertilized (a) and fertilized (b) P. centrasiaticum, respectively. Open circles and filled circles denote the well-

watered and drought-stressed plants, respectively. The beginning of rewatering is indicated by the dotted line. Values are mean $\pm \mathrm{SE}$ $(n=9)$
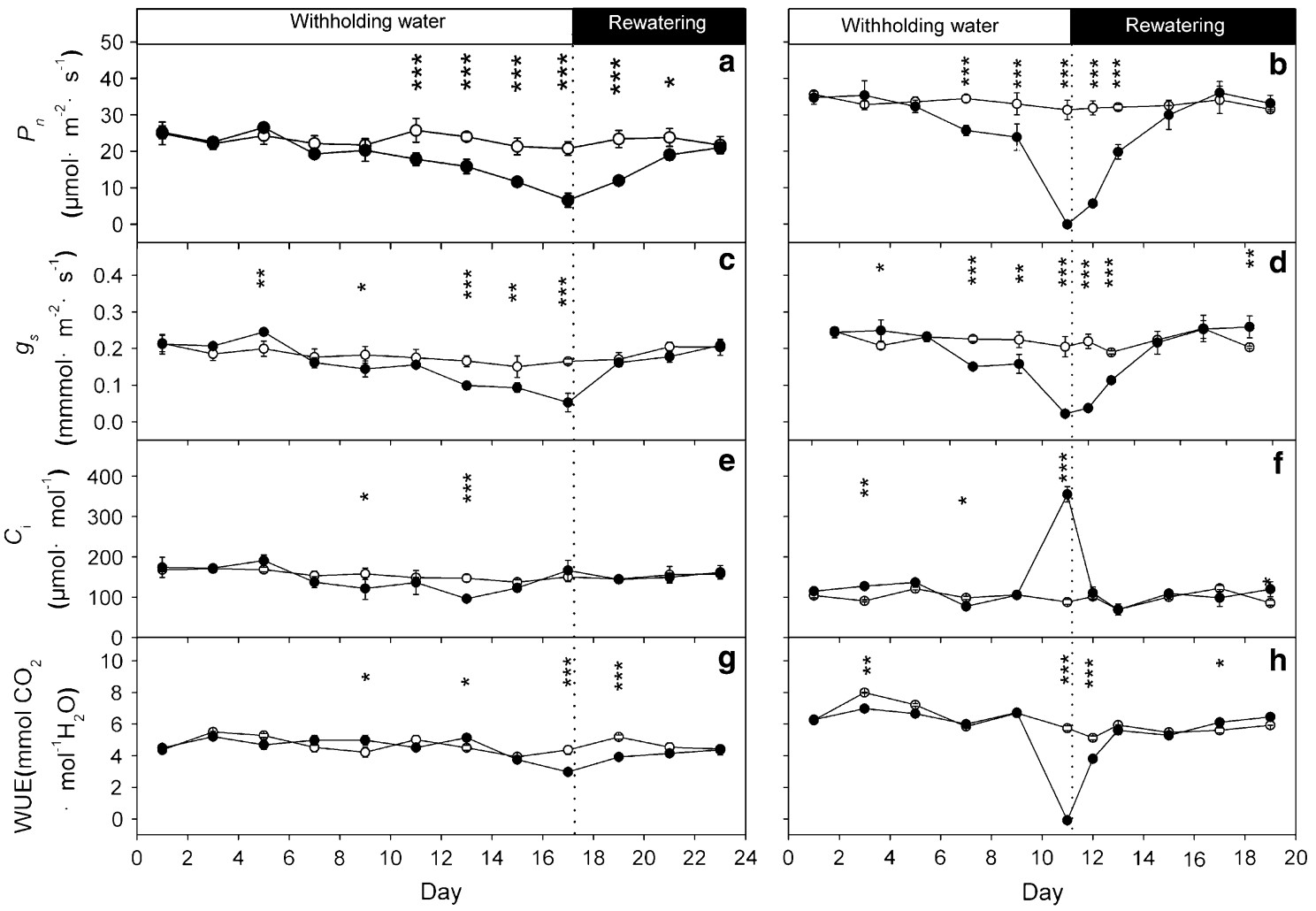

Fig. 3 Changes in gas exchange characteristics during soil drought and rewatering for unfertilized $(\mathbf{a}, \mathbf{c}, \mathbf{e}, \mathbf{g})$ and fertilized $(\mathbf{b}, \mathbf{d}, \mathbf{f}$, h) $P$. centrasiaticum, respectively. Open circles and filled circles denote the well-watered and drought-stressed plants, respectively.

showed slight changes in soil volumetric water content throughout the whole experimental period, ranging between 14.5 and $15.4 \%$ in unfertilized and between 12.5 and $14.4 \%$ in the fertilized treatment (Fig. 2).

Gas exchange characteristics

In well-watered treatments and in drought-stressed plants at an early stage, the values of leaf $P_{\mathrm{n}}, g_{\mathrm{s}}$, and WUE were
The beginning of rewatering is indicated by the dotted line. Values are mean \pm SE $(n=5)$. Significant differences between wellwatered and stressed plants at each date: $* P \leq 0.05$; $* * P \leq 0.01$; $* * * P \leq 0.001$

higher in fertilized than in unfertilized plants, but were lower at the last stage of drought and at the initial stage of rewatering. Changes in leaf $C_{i}$ (Fig. $3 \mathrm{~g}, \mathrm{~h}$ ) had a tendency opposite to that in $P_{\mathrm{n}}, g_{\mathrm{s}}$, and WUE. In addition, fertilization intensified fluctuations in the gas exchange characteristics during drought periods (Fig. 3).

After 17 days of drought, leaf $P_{\mathrm{n}}$ and $g_{\mathrm{s}}$ in unfertilized plants had decreased by 74 and $75 \%$, while in fertilized plants they decreased by 100 and $91 \%$ just after 11 days of 

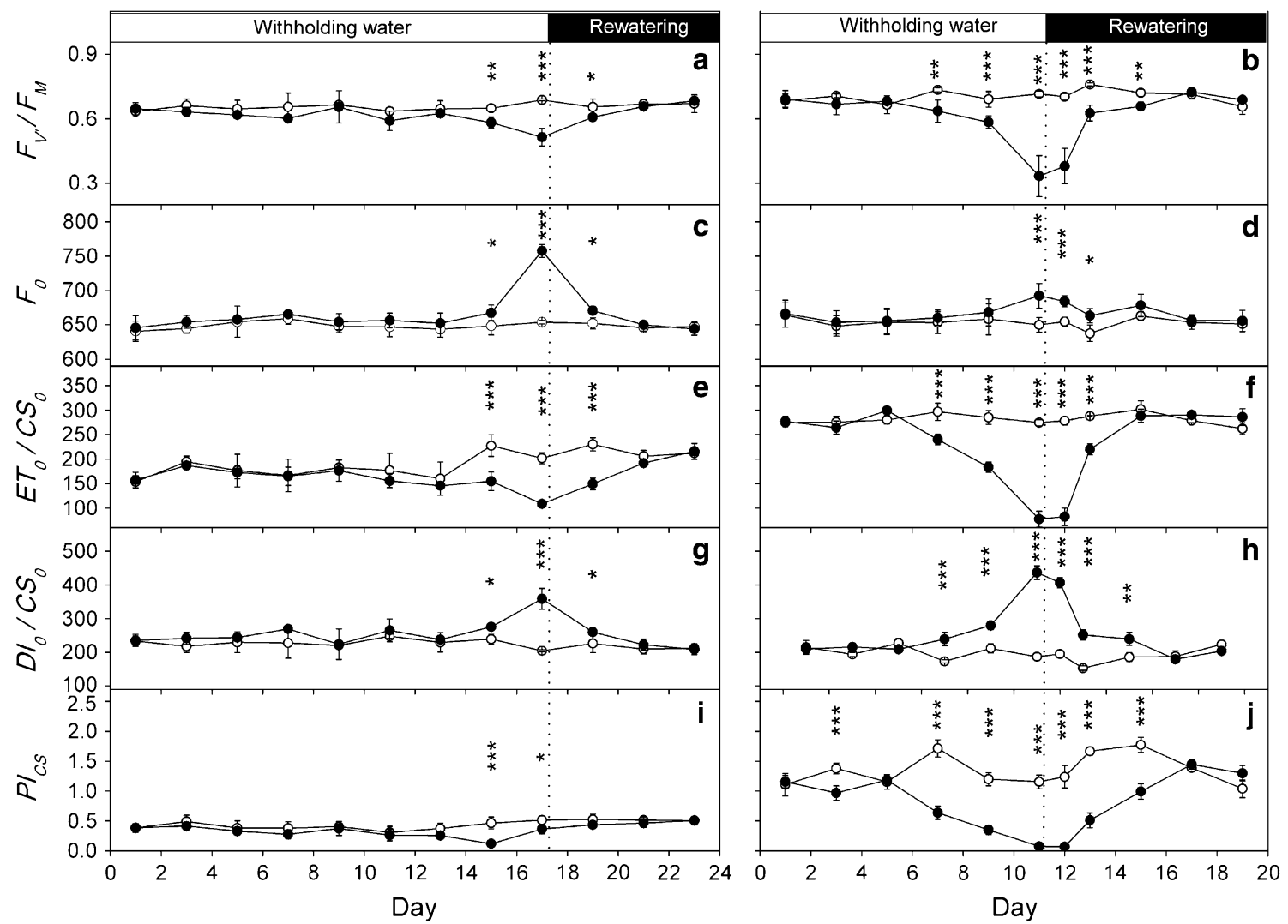

Fig. 4 Changes in chlorophyll $a$ fluorescence characteristics during soil drought and rewatering for unfertilized $(\mathbf{a}, \mathbf{c}, \mathbf{e}, \mathbf{g})$ and fertilized (b, d, f, h) P. centrasiaticum, respectively. Open circles and filled circles denote the well-watered and drought-stressed plants,

drought. However, Leaf $P_{\mathrm{n}}$ and $g_{\mathrm{s}}$ were restored to the well-watered level after irrigation for 6 days (Fig. 3). Compared to the well-watered plant, leaf $C_{i}$ decreased first and then increased during the drought period and recovered to the well-watered level after rewatering. Compared to the well-watered plant, leaf WUE remained stable initially, but decreased considerably on the last day of the drought period and recovered to the well-watered level following rewatering for 6 days (Fig. 3).

\section{Chlorophyll $a$ fluorescence characteristics}

Compared to the unfertilized plant, fertilization increased leaf $F_{\mathrm{V}} / F_{\mathrm{M}}, \mathrm{ET}_{0} / \mathrm{CS}_{0}$, and $\mathrm{PI}_{\mathrm{CS}}$ in well-watered plants and drought-stressed plants at early stages, but decreased them at the last stage of drought and initial stage of rewatering. The leaf $\mathrm{DI}_{0} / \mathrm{CS}_{0}$ had a tendency contrary to leaf $F_{\mathrm{V}} / F_{\mathrm{M}}$. Fertilization increased fluctuations in chlorophyll $a$ fluorescence characteristics during the drought period (Fig. 4).

Leaf $F_{\mathrm{V}} / F_{\mathrm{M}}, \mathrm{ET}_{0} / \mathrm{CS}_{0}$, and $\mathrm{PI}_{\mathrm{CS}}$ in unfertilized plants decreased by 21,31 , and $5 \%$ after 17 days of drought, respectively, while in the fertilized plants these decreased respectively. The beginning of rewatering is indicated by the dotted line. Values are mean $\pm \mathrm{SE}(n=5)$. Significant differences between well-watered and stressed plants at each date: $* P \leq 0.05$; $* * P \leq 0.01 ; * * * P \leq 0.001$

by 52,72 , and $94 \%$ after 11 days of drought, respectively. Leaf $F_{0}$ and $\mathrm{DI}_{0} / \mathrm{CS}_{0}$ increased during drought periods compared to the well-watered plant, and returned to the well-watered level after irrigation for 6 days (Fig. 4).

Biomass and biomass allocation between shoot and root

Total plant biomass, belowground biomass, and root:shoot ratios were significantly different between nutrient and irrigation regimes and there were interactive effects (Tables 1, 2). As expected, aboveground biomass was highly significantly affected by nutrient regimes.

Between 1.03 and $5.88 \%$ of the variation in the total biomass, belowground biomass and root:shoot ratio is explained by irrigation regimes. Nutrient regimes explain $42.16,31.18,36.93$, and $16.76 \%$ of the variation in aboveground biomass, belowground biomass, total biomass, and root:shoot ratio, respectively. Irrigation regimes $\times$ nutrient regimes explain 5.36, 2.15, and $5.56 \%$ of the variation in the belowground biomass, total biomass, and root:shoot ratio, respectively. Both irrigation regimes and irrigation regimes $\times$ nutrient regimes had no significant effect on the aboveground biomass (Table 2). 
Table 1 Biomass (above ground, below ground and total) and root:shoot ratio for $P$. centrasiaticum

\begin{tabular}{lcccc}
\hline & Aboveground biomass & Belowground biomass & Total biomass & Root:shoot ratio \\
\hline No fertilization, well watered & $1.56 \pm 0.20$ & $4.10 \pm 0.31$ & $5.65 \pm 0.50$ & $2.67 \pm 0.16$ \\
No fertilization, drought stressed & $0.80 \pm 0.04$ & $3.66 \pm 0.17$ & $4.46 \pm 0.20$ & $4.57 \pm 0.11$ \\
Fertilization, well watered & $21.86 \pm 3.07$ & $35.72 \pm 2.54$ & $57.58 \pm 5.11$ & $1.69 \pm 0.21$ \\
Fertilization, drought stressed & $19.45 \pm 3.28$ & $16.74 \pm 1.24$ & $36.19 \pm 2.08$ & $0.93 \pm 0.19$ \\
\hline
\end{tabular}

Values are mean $\pm \mathrm{SE}(n=3)$

Table 2 Summary of GLM results, examining the effects of irrigation regimes and nutrient regimes on biomass and biomass allocation between shoots and roots, ANOVA

\begin{tabular}{|c|c|c|c|c|c|c|c|c|c|}
\hline & \multirow[t]{2}{*}{$d f$} & \multicolumn{2}{|c|}{ Aboveground biomass } & \multicolumn{2}{|c|}{ Belowground biomass } & \multicolumn{2}{|c|}{ Total biomass } & \multicolumn{2}{|c|}{ Root:shoot ratio } \\
\hline & & $F$ & SS $(\%)$ & $F$ & SS $(\%)$ & $F$ & SS $(\%)$ & $F$ & SS $(\%)$ \\
\hline Irrigation regimes & 1 & 0.50 & $0.27 \mathrm{~ns}$ & 46.53 & $5.88 * *$ & 16.58 & $2.69 * *$ & 11.10 & $1.03 * *$ \\
\hline Nutrient regimes & 1 & 74.93 & $42.16^{* *}$ & 246.73 & $31.18 * *$ & 227.47 & $36.93 * *$ & 181.29 & $16.76^{* *}$ \\
\hline Irrigation regimes $\times$ nutrient regimes & 1 & 0.14 & $0.08 \mathrm{~ns}$ & 42.41 & $5.36^{* *}$ & 13.25 & $2.15 * *$ & 60.14 & $5.56 * * *$ \\
\hline Total & & & 42.16 & & 42.42 & & 41.77 & & 23.35 \\
\hline
\end{tabular}

Intercept was included in the model. $d f$ degrees of freedom. SS (\%): proportion of sum of squares to the total sum of squares (type I); Asterisks denote significance at $P<0.05(*), P<0.01(* *)$ and $P<0.001(* * *)$

\section{Discussion and conclusions}

Photosynthetic performance and biomass traits during drought stress and recovery

Withholding water for 17 and 11 days resulted in a successive limitation of water availability under both nutrient regimes in $P$. centrasiaticum (Fig. 2). Initially, leaf $P_{\mathrm{n}}, g_{\mathrm{s}}$, $C_{i}$, and WUE remained relatively stable, similar to the observation in well-watered plants. Following soil water content during the drought periods, leaf $P_{\mathrm{n}}$ declined in parallel with $g_{\mathrm{s}}$ after drought stress for both unfertilized and fertilized $P$. centrasiaticum (Fig. 3). The process when leaf $P_{\mathrm{n}}$ declined in parallel with $g_{\mathrm{s}}$ could be distributed into two stages-leaf $C_{i}$ first decreased and then increased. Leaf $C_{i}$ decreased at the early and middle stage of drought, when stomatal limitations seemed to account mainly for this reduction of photosynthesis. Stomatal closure protects against further water loss and irreversible cell dehydration under progressing soil drought conditions (Galle et al. 2007). However, leaf $C_{i}$ increased at the last stage of drought, which suggested increased limitations to photochemistry by nonstomatal processes (Galle et al. 2007). An overestimated $C_{i}$ could result from heterogeneous (or "patch") stomatal closure and cuticular conductance which are the two main problems invalidating $C_{i}$ calculations under drought (Flexas et al. 2004b). Furthermore, the dramatic decreases in $P_{\mathrm{n}}$ and $g_{\mathrm{s}}$ and sharp increases in $C_{i}$ (Fig. 3) suggested that non-stomatal limitations to photosynthesis dominated at the last stage of drought (Flexas et al. 2004a), indicating that the photosynthetic apparatus of $P$. centrasiaticum was damaged, presumably due to decreases in photochemistry and Rubisco activity (Flexas et al. 2006b). Besides metabolic impairment, it is likely that the concentration of $\mathrm{CO}_{2}$ was not high enough to overcome diffusive resistances within the leaf, suggesting a possibly lower mesophyll conductance or chloroplast conductance. The malfunction of the photosynthetic apparatus may also reduce the efficiency of electron transport for the photosynthetic reactions (Figs. 3, 4) (Galle et al. 2007).

$F_{\mathrm{V}} / F_{\mathrm{M}}, \mathrm{ET}_{0} / \mathrm{CS}_{0}$, and $\mathrm{PI}_{\mathrm{CS}}$ were considerably downregulated during the day at the last stage of drought (Fig. 4). This suggested that the trapping probability of PS II and the electron transport flux were inhibited under drought. However, the reverse tendency was observed in $F_{0}$ and $\mathrm{DI}_{0} /$ $\mathrm{CS}_{0}$ under drought, reflecting a possible case of photoinhibition (Force et al. 2003). Removal of excess excitation energy via thermal dissipation increased during droughtinduced suppression of $P_{\mathrm{n}}$ (Figs. 3, 4). This indicated a flexible adjustment of capture and transfer of excitation energy within the photosynthetic apparatus (Krause and Weis 1991), leading to an increased electron flow to alternative sinks, such as photorespiration (Ort and Baker 2002). This even seemed to be present at the last stage of drought and led to an almost complete suppression of $P_{\mathrm{n}}$ (Figs. 3, 4), consistent with previous studies (Galle and Feller 2007).

Although differences in the severity and duration of drought stress have been observed in both nutrient regimes, the recovery pattern of previously stressed $P$. centrasiaticum 
was almost the same (Figs. 3, 4). There are indications that intensity and duration of stress affect the velocity of recovery after relief (Miyashita et al. 2005; Flexas et al. 2006a). During the rewatering phase, photosynthetic performance recovered gradually under both nutrient regimes in $P$. centrasiaticum. Initially, non-stomatal limitations seemed to prevail, because $P_{n}$ and $g_{\mathrm{s}}$ of previously drought-stressed $P$. centrasiaticum recovered only partially, while $C_{i}$ was restored within 1 or 2 days of rewatering (Fig. 3). Besides metabolic impairment, it is equally likely that the concentration of $\mathrm{CO}_{2}$ was not high enough to overcome diffusive resistances within the leaf, thus photosynthesis may be more restricted by the chloroplast's capacity to fix $\mathrm{CO}_{2}$ (metabolic limitations) than by the increased diffusive resistance (Yordanov et al. 2000; Flexas et al. 2004a) during the early stage of drought periods.

Recovery of gas exchange characteristics was observed following 1-4 days of rewatering (Fig. 3). Earlier studies (Souza et al. 2004; Galle et al. 2007) reported that plants reached levels of $P_{\mathrm{n}}$, and $g_{\mathrm{s}}$ similar to those found in wellwatered plants. In contrast, Miyashita et al. (2005) reported that the fractional recovery in $P_{\mathrm{n}}$ was higher than that of $g_{\mathrm{s}}$. Galle and Feller (2007) reported that $P_{\mathrm{n}}$ recovered completely within 4 weeks in stressed beech, while $g_{\text {s }}$ remained permanently lower in drought-stressed plants than in wellwatered plants. Therefore, differences in recovery of $P_{\mathrm{n}}$ and $g_{\mathrm{s}}$ may be species specific or stress specific and require further investigations (Flexas et al. 2004a; Galle et al. 2007). Recovery of chlorophyll $a$ fluorescence characteristics was observed following 2-6 days of rewatering. This was consistent with previous studies (Souza et al. 2004; Galle and Feller 2007; Galle et al. 2007).

It might be speculated that physiological adjustments at the leaf level to minimize water loss under stressful conditions remained during rewatering to reduce future stress (Galle and Feller 2007; Galle et al. 2007; Luo et al. 2011). This mechanism could account for the delayed recovery of photochemistry of drought-stressed $P$. centrasiaticum during rewatering periods. Such observations have also been documented by Souza et al. (2004) for cowpea exposed to drought and recovery.

Additionally, drought-induced changes on the whole plant level might also play a role in adaptation to drought, such as leaf morphology or biomass allocation (Niinemets and Kull 1998; Bréda et al. 2006). Compared to wellwatered plants, drought and rewatering decreased total, aboveground, and belowground biomass under both nutrient regimes. Drought and rewatering increased the root:shoot ratio under the non-fertilized regime, but decreased the root:shoot ratio under the fertilized regime (Table 1). This observation is partly in agreement with the general theory, that is, the root:shoot ratio increased with the decrease of water availability.
Photosynthetic performance and biomass traits under different soil nutrient regimes

Fertilization has contributed to an accelerated loss of water (Fig. 2), which resulted in the drought period for fertilized treatment being shorter (11 days) than that for unfertilized treatment (17 days). In agreement with the study of $\mathrm{Wu}$ et al. (2008), fertilization increased the leaf $P_{\mathrm{n}}, g_{\mathrm{s}}$, WUE, $F_{\mathrm{V}} / F_{\mathrm{M}}, \mathrm{ET}_{0} / \mathrm{CS}_{0}$, and $\mathrm{PI}_{\mathrm{CS}}$ in well-watered and droughtstressed plants at an early stage (Figs. 3, 4), suggesting that fertilization could enhance potential photosynthetic capacity during the early drought period. The results also support the general theory that supply of one limited resource can enhance the use efficiency of other resources (Fig. 3) (Wu et al. 2008). However, the values were lower at the last stage of drought and initial stage of rewatering than those in unfertilized plants (Figs. 3, 4), suggesting that fertilization aggravated the stress during the period. Thus, fertilization increased fluctuations in the gas exchange and chlorophyll $a$ fluorescence characteristics during drought period, which indicated that fertilization accelerated the process of drought and aggravated stress under severe drought condition in $P$. centrasiaticum. This was mainly due to the fact that fertilization increased the total biomass, aboveground biomass, and belowground biomass remarkably for both irrigation regimes (Table 1). However, fertilization decreased the root:shoot ratio for both irrigation regimes (Table 1), which was in agreement with the results of (Huang et al. 2009) and the general theory, that is, plants often allocate a greater proportion of their biomass to the root system in an infertile environment. The effect of fertilization was the largest source of variation for these biomass traits and allocation (Table 2), which was consistent with a previous study (Huang et al. 2009).

In summary, a similar pattern of photosynthetic adjustments during drought and rewatering was observed in $P$. centrasiaticum saplings. Although the acceleration of the drought progress differed between nutrient regimes, the recovery pattern of previously stressed $P$. centrasiaticum was almost the same (Figs. 3, 4). Reversible down-regulation of PSII photochemistry and enhanced thermal dissipation of excess excitation energy $\left(\mathrm{DI}_{0} / \mathrm{CS}_{0}\right)$ contributed to an enhanced photo-protection in progressively droughtstressed plants (Figs. 3, 4). A tight network of photoprotective mechanisms minimized stress-induced damages to the photosynthetic apparatus in both nutrient regimes. Thus, a rapid recovery of photosynthetic performance took place, even after an almost complete suppression of $P_{\mathrm{n}}$. It can be concluded that $P$. centrasiaticum seems to be capable of withstanding and surviving extreme drought events. This characterizes and underlines the capacity of $P$. centrasiaticum to withstand and survive summer drought in the Horqin Sandy Land. 
However, fertilization accelerated the process of drought and aggravated stress under extreme drought events in $P$. centrasiaticum, even resulting in death of the plants $(22 \%$ of the fertilized plants were dead in the late growing season of 2009 under natural precipitation conditions). Thus, fertilization should be cautiously used in vegetation restoration in the Horqin Sandy Land.

Author contribution Yayong Luo and Xueyong Zhao designed the experiments. Yayong Luo, Hao Qu, Xiaoan Zuo, and Shaokun Wang performed the experiments. Wenda Huang and Yongqing Luo carried out the analysis of data. Min Chen plotted the figures. Yayong Luo and Xueyong Zhao prepared the manuscript.

Acknowledgments The authors thank all staff at Naiman Desertification Research Station, Chinese Academy of Sciences (CAS). We wish to thank the anonymous reviewers for valuable comments on the manuscript. This paper was financially supported by the National Science and Technology Support Program (2011BAC07B02), National Natural Science Foundation of China (41201249, 41071185, 41271007), the Knowledge Innovation Program of the Chinese Academy of Sciences (KZCX2-EW-QN313), and the National Basic Research Program of China (2009CB421303). Prof. O. Andrén edited and revised late versions of the manuscript, supported by a 'Professorship for Senior International Scientists' Grant (Y229D91001) by the Chinese Academy of Sciences.

Open Access This article is distributed under the terms of the Creative Commons Attribution License which permits any use, distribution, and reproduction in any medium, provided the original author(s) and the source are credited.

\section{References}

Andrén O, Zhao X, Liu X (1994) Climate and litter decomposition in Naiman, Inner Mongolia, China. Ambio 23:222-224

Bréda N, Huc R, Granier A, Dreyer E (2006) Temperate forest trees and stands under severe drought: a review of ecophysiological responses, adaptation processes and long-term consequences. Ann For Sci 63:625-644

Chen SP, Bai YF, Zhang LX, Han XG (2005) Comparing physiological responses of two dominant grass species to nitrogen addition in Xilin River Basin of China. Environ Exp Bot 53:65-75

Flexas J, Bota J, Cifre J, Escalona J, Galmés J, Gulias J, Lefi E, Martinez-Canellas S, Moreno M, Ribas-Carbó M (2004a) Understanding down-regulation of photosynthesis under water stress: future prospects and searching for physiological tools for irrigation management. Ann Appl Biol 144:273-283

Flexas J, Bota J, Loreto F, Cornic G, Sharkey T (2004b) Diffusive and metabolic limitations to photosynthesis under drought and salinity in $\mathrm{C}_{3}$ plants. Plant Biol (Stuttg) 6:269-279

Flexas J, Bota J, Galmés J, Medrano H, Ribas-Carbó M (2006a) Keeping a positive carbon balance under adverse conditions: responses of photosynthesis and respiration to water stress. Physiol Plant 127:343-352

Flexas J, Ribas-Carbó M, Bota J, Galmés J, Henkle M, Martínez-Ca ellas S, Medrano H (2006b) Decreased Rubisco activity during water stress is not induced by decreased relative water content but related to conditions of low stomatal conductance and chloroplast $\mathrm{CO}_{2}$ concentration. New Phytol 172:73-82

Force L, Critchley C, van Rensen J (2003) New fluorescence parameters for monitoring photosynthesis in plants. Photosynth Res 78:17-33

Galle A, Feller U (2007) Changes of photosynthetic traits in beech saplings (Fagus sylvatica) under severe drought stress and during recovery. Physiol Plant 131:412-421

Galle A, Haldimann P, Feller U (2007) Photosynthetic performance and water relations in young pubescent oak (Quercus pubescens) trees during drought stress and recovery. New Phytol 174:799-810

Huang Y, Zhao X, Zhang H, Huang G, Luo Y, Japhet W (2009) A comparison of phenotypic plasticity between two species occupying different positions in a successional sequence. Ecol Res 24:1335-1344

Krause G, Weis E (1991) Chlorophyll fluorescence and photosynthesis: the basics. Annu Rev Plant Biol 42:313-349

Lin L, Chen J, Cai C (2012) High rate of nitrogen fertilization increases the crop water stress index of corn under soil drought. Commun Soil Sci Plant 43:2865-2877

Luo Y, Zhao X, Zhou R, Zuo X, Zhang J, Li Y (2011) Physiological acclimation of two psammophytes to repeated soil drought and rewatering. Acta Physiol Plant 33:79-91

Miyashita K, Tanakamaru S, Maitani T, Kimura K (2005) Recovery responses of photosynthesis, transpiration, and stomatal conductance in kidney bean following drought stress. Environ Exp Bot 53:205-214

Niinemets Ü, Kull O (1998) Stoichiometry of foliar carbon constituents varies along light gradients in temperate woody canopies: implications for foliage morphological plasticity. Tree Physiol 18:467-479

Ort D, Baker N (2002) A photoprotective role for $\mathrm{O}_{2}$ as an alternative electron sink in photosynthesis? Curr Opin Plant Biol 5:193

Ortuno MF, Alarcon JJ, Nicolas E, Torrecillas A (2005) Sap flow and trunk diameter fluctuations of young lemon trees under water stress and rewatering. Environ Exp Bot 54:155-162

Perez-Perez JG, Syvertsen JP, Botia P, Garcia-Sanchez F (2007) Leaf water relations and net gas exchange responses of salinized Carrizo citrange seedlings during drought stress and recovery. Ann Bot 100:335-345

Radin JW, Ackerson RC (1981) Water relations of cotton plants under nitrogen deficiency III. Stomatal conductance, photosynthesis, and abscisic acid accumulation during drought. Plant Physiol 67:115-119

Santesteban L, Miranda C, Royo J (2009) Effect of water deficit and rewatering on leaf gas exchange and transpiration decline of excised leaves of four grapevine (Vitis vinifera L.) cultivars. Sci Hortic 121:434-439

Souza R, Machado E, Silva J, Lagoa A, Silveira J (2004) Photosynthetic gas exchange, chlorophyll fluorescence and some associated metabolic changes in cowpea (Vigna unguiculata) during water stress and recovery. Environ Exp Bot 51:45-56

Wu F, Bao W, Li F, Wu N (2008) Effects of water stress and nitrogen supply on leaf gas exchange and fluorescence parameters of Sophora davidii seedlings. Photosynthetica 46:40-48

Xu H, Li Y, Xu GT, Zou T (2007) Ecophysiological response and morphological adjustment of two Central Asian desert shrubs towards variation in summer precipitation. Plant Cell Environ 30:399-409

Yordanov I, Velikova V, Tsonev T (2000) Plant responses to drought, acclimation, and stress tolerance. Photosynthetica 38:171-186

Zhao H-L, He Y-H, Zhou R-L, Su Y-Z, Li Y-Q, Drake S (2009) Effects of desertification on soil organic $\mathrm{C}$ and $\mathrm{N}$ content in sandy farmland and grassland of Inner Mongolia. Catena 77:187-191

Zhou R-L, Li Y-Q, Zhao H-L, Drake S (2008) Desertification effects on $\mathrm{C}$ and $\mathrm{N}$ content of sandy soils under grassland in Horqin, northern China. Geoderma 145:370-375 